\title{
Examination of in-cloud sulfate chemistry using a different model initialization
}

\author{
Vlado Spiridonov $^{1}$ (D) $\cdot$ Mladjen Ćurić $^{2} \cdot$ Boro Jakimosvki $^{3}$
}

Received: 30 August 2018 / Accepted: 11 October 2018 / Published online: 13 December 2018

(C) The Author(s) 2018

\begin{abstract}
We first examine characteristics of in-cloud sulfate chemistry of a mid-latitude convective cloud using a different model initialization. Specifically, we studied the relative importance of convection on sulfate aerosol transport and redistribution. The analysis is focused on 4 April 2000, when considerable dust transport is evidenced with high concentration and wet deposition of sulfate aerosol measured at the European Monitoring Environmental Program (EMEP) station located in the western mountain part of the Republic of Macedonia. The cloud-resolving model coupled with aqueous sulfate chemistry module has been employed to simulate the sulfate aerosol aqueous chemistry and wet deposition. The modeled results and sensitivities under various initializations are evaluated and compared with a ground-based measurements and laboratory analysis. The results indicate that the local environmental profiles derived from $2.5 \mathrm{~km}$-scale WRF model provides a better cloud model initialization, capable of realistic representation of sub-grid-scale processes which are not adequately resolved by the WRF model with a coarser grid resolution. The method also shows a relatively good performance in simulation of cloud physical processes which take place in-cloud and the near cloud environment, cloud-chemistry interactions, relevant to sulfate acidification and sulfate deposition, which allows a more accurate quantitative assessment of sulfate concentration and $\mathrm{pH}$ values. Analysis also indicated that scavenging and oxidation are the principal processes affecting sulfate production, participating with 33 and $46 \%$, respectively. Turning off the ice-phase processes leads to overprediction of sulfate aerosol production for about $8 \%$ relative to the base run. The verification analysis indicates that the numerical simulation initialized with a $2.5-\mathrm{km}$-scale WRF model shows a higher correlation coefficient with observations compared to other runs. This approach of initialization based on WRF conditions provides a scientific contribution by evaluating simulations of convective clouds in Macedonia against ground-based meteorological and chemical data, as well as by using the model to understand the driving processes affecting sulfate production and wet deposition.
\end{abstract}

Keywords A cloud-chemistry model $\cdot$ WRF initialization $\cdot$ Sulfate aerosol $\cdot$ Wet deposition $\cdot$ Acid precipitation

Electronic supplementary material The online version of this article (https://doi.org/10.1007/s11869-018-0632-y) contains supplementary material, which is available to authorized users.

Vlado Spiridonov

vlado.spiridonov@univie.ac.at

1 Department of Meteorology and Geophysics, Faculty of Earth Science, Geography and Astronomy, University of Vienna, 1090 Vienna, Austria

2 Institute of Meteorology, University of Belgrade, Belgrade, Serbia

3 Faculty of Computer Science and Engineering, Ss. Cyril and Methodius University in Skopje, Skopje, Republic of Macedonia

\section{Introduction}

Convection plays a significant role in vertical transport of atmospheric pollutants, redistribution, and wet deposition. Because of these processes the effect of convection is critical to our understanding of air quality, chemistry-climate and the effect of acidic precipitation on the surface (Wang and Prinn 2000; Barth et al. 2007b; Tao et al. 2012). Many previous studies examined sulfate chemistry processes within cloud using one-dimensional models constraining the physical interpretation of the modeled results (Hales 1982; Walcek and Taylor 1986; Taylor 1989), or three-dimensional cloud-chemistry model used by Tremblay and Leighton (1986) and Niewiadomski (1989), but they primarily focused on warm convective clouds. Scavenging, as important process for the 
redistribution of chemical species by convective clouds, has been studied by using different methods (e.g. Easter and Hales 1983; Giorgi and Chameides 1986; Cohan et al. 1999; Crutzen and Lawrence 2000). Wang and Chang (1993a, b) developed and applied a three-dimensional cloud-chemistry model to study deep convection and chemical processes, transformations, and redistribution of pollutants. The results for a similar research study using different model versions with upgraded microphysics or chemistry parameterizations have been discussed (Wang and Crutzen 1995; Kreidenweis et al. 1997; Wang and Prinn 1998; Wang and Prinn, 2000; Spiridonov and Ćurić 2003, 2005, 2009). Barth et al. (2001) examined the redistribution of gases of varied solubility during deep convection, while Yin et al. (2001) used a 2D meteorological model with full microphysics and spectral method of gas scavenging. Ekman et al. $(2004,2006)$ coupled the cloud-resolving model with an explicit aerosol module to examine aerosol chemistry during deep convection. The evaluation of the results from a number of sensitivity runs implied that accumulation mode aerosols, which play as main cloud condensation nuclei $(\mathrm{CCN})$, are completely removed with heavy precipitation, while nucleation mode aerosols grow fast due to coagulation of aerosols and condensation of S (VI). They also found that the size distribution of aerosols strongly influences their behavior in convective cloud. Stuart and Jacobson (2003) investigated the freezing transport mechanism and retention of volatile chemical species in clouds. They argued that for a highly soluble species, the cloud model parameterizations which assume that volatiles escape during freezing tend to overpredict a gas-transfer process between two phases. In addition, their results imply that for chemical species with low Henry's Law coefficient, freezing conditions have significant impact on retention of chemicals on ice particles. Barth et al. (2007a) incorporated a simple gas-aqueous chemistry parameterization scheme within Weather Research and Forecasting Model (WRFAqChem) to examine the redistribution of some chemical species by deep convection for the 10 July 1996 STERAO storm. Results indicate significant difference in vertical redistributions of the soluble species considering the freezing transport mechanism (retention and degassing) and also showed some uncertainties in simulation of the influence of deep convection on upper tropospheric composition and chemistry. The impact of dust on naturally produced particulate matters (PMs) in the Mediterranean and North Atlantic is studied by Kallos et al. (2006, 2007). Later, some improvements of their modeling system have been provided (see Spyrou, et al. 2010) by incorporating new features for the description of the planetary boundary layer (PBL) and some dust features. A few years later, Pérez et al. (2011) developed a multiscale atmospheric dust model coupled with the non-hydrostatic multiscale model (NMMB; Janjic 2005) with collaboration of NOAA/NCEP, NASA, Barcelona
Supercomputing Center (BSC-CNS) and the International Research Institute for Climate and Society (IRI). Langmann et al. (2008) employed a regional-scale atmospheric climatechemistry/aerosol model with incorporating aerosol module (REMOTE) to simulate aerosol distribution over Europe. The results from their evaluation and comparative study suggest about the importance of dry deposition fluxes on atmospheric burden concentration. They also found the importance of incorporation of a diurnal cycle in anthropogenic emission fluxes in the model configuration, which will significantly improve the ozone and sulfate concentrations. Tuccella et al. (2012) employed WRF model coupled with chemistry (WRF-Chem) without aerosol-cloud feedback to examine the transport of gases and aerosols over Europe. While their meteorology results well fit with the observation, model tends to underpredict sulfate by a factor of 2 , due to the missing parameterization of aqueous-phase oxidation processes of sulfur dioxide $\left(\mathrm{SO}_{2}\right)$ by hydrogen peroxide $\left(\mathrm{H}_{2} \mathrm{O}_{2}\right)$ and $\mathrm{O}_{3}$, as important in sulfate production. Wonaschuetz et al. (2012) used airborne measurements and parcel model to examine the effects of shallow convection on vertical distribution of aerosol and gases. They emphasized the role of convective transport in altering the vertical distribution of aerosol chemistry and aqueous-phase production of aerosol mass (sulfate and organics). A coupled WRF/ HYSPLIT numerical modeling approach has been adopted by Yerramilli et al. (2012) to examine the atmospheric dispersion of $\mathrm{SO}_{2}$ and $\mathrm{NOx}$ from elevated point sources in the Mississippi Gulf Coast region. Results indicated the potential benefit of the method of source identification through back trajectories and the strong influence of the atmospheric flow patterns on pollutant dispersion and provided better understanding of sources of air pollution. Bae et al. (2012) incorporated a newly developed below-cloud scavenging scheme in the Community Multiscale Air Quality (CMAQ) model to examine the effects of below-cloud scavenging on aerosol concentrations over East Asia during spring 2001. The results from the simulations of wet deposition fluxes of aerosols by the new scheme, show better agreement with observations. The topography effect on convective cloud evolution and its impact on sulfate transport and redistribution in non-polluted and polluted environment were examined using Advanced Regional Prediction System (ARPS) with coupled aqueous sulfate chemistry sub-model developed by Vujović et al. (2014). The results indicate that topography greatly affects the vertical transport of sulfate aerosol. In addition, they found that alternately turning off topography leads to underprediction of sulfur mass at the surface by about 25 $30 \%$. Berg et al. (2015) incorporated new chemical and microphysical parameterization schemes in WRF-Chem model incorporating some micro- and macrophysical parameters including the aqueous chemistry of aerosols and trace gases and 
wet deposition in warm clouds. The main objective of their work is to improve the regional-scale forecast and the cloudaerosol processes and their interactions. This study revealed that these upgraded schemes in WRF-Chem contributed to better forecast of cloud droplet number concentration compared to a simple gas-aqueous chemistry parameterization scheme developed by Barth et al. (2007a) or WRF-Chem simulation without aerosol-cloud parameterization employed by Tuccella et al. (2012). This modification also demonstrated ability for a better treatment of cloud-aerosol interactions and its life cycle in a realistic manner over regional to synoptic scales. In addition, numerical studies by Barth et al. (2016) examined the role of deep convection on transport and redistribution of trace gases and aerosols and scavenging by thunderstorms observed over the central USA during The Deep Convective Clouds and Chemistry Project (DC3) field experiments in the central USA using for the first time a full set of chemical measurements and ground-based and remotesensing observations. Results show comparable $\mathrm{H}_{2} \mathrm{O}_{2}$ scavenging efficiency with former studies and also suggest that the thermodynamic environment plays a role in the degree of scavenging. As part of this field campaign, Bela et al. (2016) reported that high-resolution 1-km WRF-Chem with a simple wet scavenging scheme showed ability to simulate storm dynamics and tracer transport quite well and that scavenging efficiency is sensitive to retention fraction of chemical species. However, they suggested that multiphase chemistry cannot be well simulated without detailed representation of the aqueousphase chemistry in the model.

The main motivation of the present study is to examine the in-cloud and subcloud sulfate aerosol processes during a dust transport over the South-Western part of Macedonia. It is achieved using the local environmental profiles derived from the numerical weather prediction (NWP) model with different horizontal grid resolution at that time/location to initialize a separate cloud-chemistry model. This models a much smaller sub-domain over the location of interest at a significantly refined horizontal and vertical resolution capable of realistically simulating convective cloud-chemistry processes. It makes the model more suitable for the sensitivity simulations and shows a better skill in resolving of cloud-chemical processes. Two sets of numerical simulations were done: varying the meteorological initialization and alternately turning off certain chemical processes participating in sulfate production. In "Model formulation and description" section, we briefly describe the convective cloud model background and sulfate chemistry sub-model, numerical technique, and boundary conditions. Numerical experiments, initial conditions, and experimental setup are explained in "Observational analysis and model setup" section. Then, we focus on evaluation and validation of the results against the observation. Finally, results are discussed and summarized.

\section{Model formulation and description}

\section{A cloud-chemistry model}

A cloud-chemistry model is a three-dimensional (3D) nonhydrostatic, compressible time-dependent, model with dynamic scheme from Klemp and Wilhelmson (1978), thermodynamics proposed by Orville and Kopp (1977), and bulk microphysical parameterization scheme according to Lin et al. (1983). This model version is coupled with a sulfate chemistry sub-model to simulate the chemical and physical processes in convective clouds. Sulfate chemistry is dominated by aqueous-phase reactions on the time scales typical for convective clouds studied. Therefore, gas-phase chemistry could be neglected in the present study. The chemical fields in the model and sulfate aerosols expressed in terms of mixing ratios are advected simultaneously with the dynamic and bulk microphysical fields without aerosol bin size used in our model. Only sulfate chemistry is considered in the present version of the model. Our chemical sub-model uses as basic mathematical framework a set of conventional continuity equations for each chemical species associated with the corresponding hydrometeor field (e.g., cloud water, cloud ice, rain, hail and snow).The present research describes in detail sulfate chemistry as it was done in a study by Taylor (1989). Sulfate production and subsequent deposition through precipitation are considered by the following processes: chemical reactions (gas conversion + oxidation), scavenging of aerosol particles, and transfer of sulfate aerosol among different hydrometeor fields by the microphysical transitions. A schematic of the aqueousphase sulfate processes is shown in Supplemental Material Fig. S1, while the microphysical processes and chemistryrelated conversion terms for $\mathrm{SO}_{4}{ }^{2-}$ in air and in different water categories and the name associated with each of them in the model is listed in Supplemental Material Tab. S1. The equilibrium $\left[\mathrm{H}^{+}\right]$concentration in cloud water and rainwater is calculated under the assumption that hydrogen ion concentration $\left[\mathrm{HSO}_{3}{ }^{-}\right]$is the dominant form of S (IV). Since the S (IV) mole fraction of $\left[\mathrm{SO}_{3}{ }^{-2}\right]$ is less than $3 \%$ for the $\mathrm{pH}$ range found in these clouds $(3 \leq \mathrm{pH} \leq 5.5)$, only $\left[\mathrm{HSO}_{3}{ }^{-}\right]$is included in the charge balance equation. Thus, the calculation of the cloud water $\mathrm{pH}$ and rainwater $\mathrm{pH}$ is based on the equilibrium hydrogen ion concentration for $\left[\mathrm{H}^{+}\right]$, which is given by the simple charge balance equation (Taylor 1989):

$\left[\mathrm{H}^{+}\right]=0.5\left\{2\left[\mathrm{SO}_{4}^{2-}\right]-\left[\mathrm{NH}_{4}^{+}\right]+\left(\left(2\left[\mathrm{SO}_{4}^{2-}\right]-\left[\mathrm{NH}_{4}^{+}\right]\right)^{2}+4 \mathrm{~K}_{\mathrm{H}}{ }^{*} \mathrm{p}_{\mathrm{SO}_{2}}+4 \mathrm{~K}_{\mathrm{w}}\right)^{0.5}\right\}(1)$

More information regarding the cloud physics, sulfate chemistry parameterization, initial and boundary conditions, and model initialization could be found in Telenta and Aleksic (1988), Spiridonov and Ćurić (2003, 2005), and Barth et al. (2007b). 
Fig. 1 WRF-Chem forecast of dust concentration $(\mu \mathrm{g} / \mathrm{kg}$-dry air) on 3 April 2000 at 1200 UTC. a Dust distribution over the whole integration domain. b The forecast of dust concentration over Macedonia, with dust size bin 5 and $8.0 \mu \mathrm{m}$ effective radius of the finest dust particles
WRF-CHEM v.4.0 Forecast of dust (ug/kg dryair) 4 April 2000 12:00 UTC

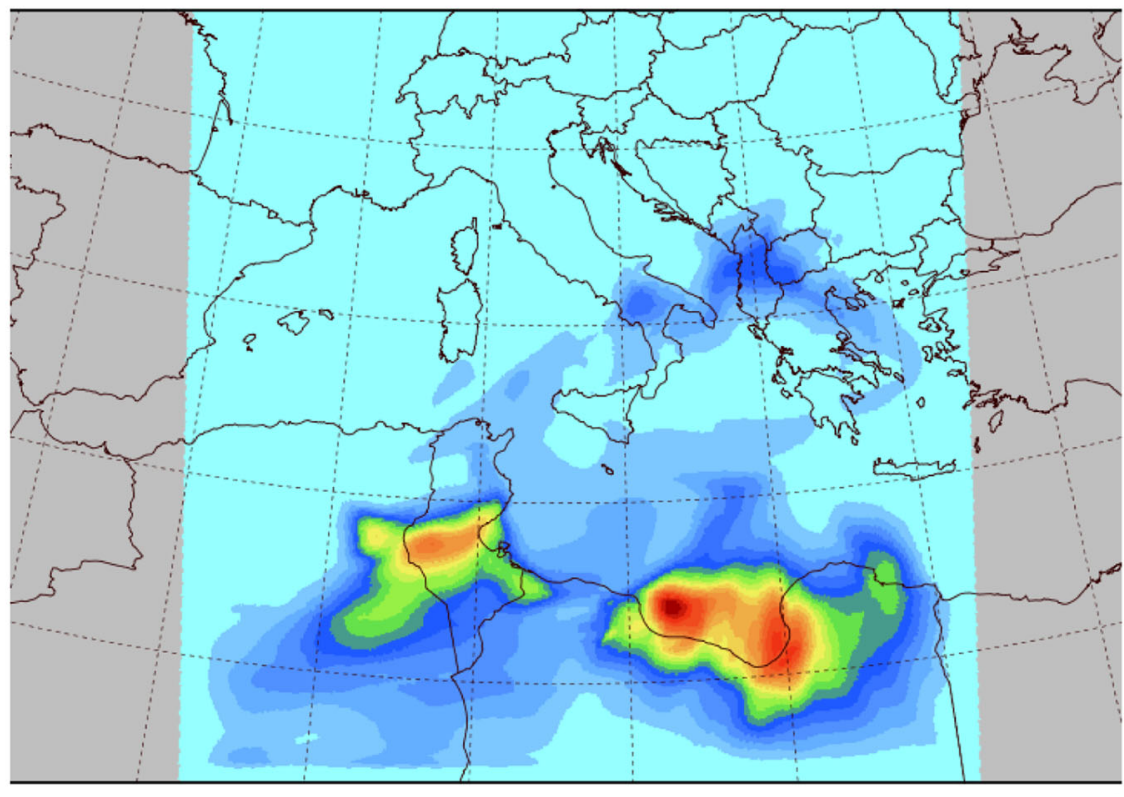

DUST_5 (ug/kg-dryair)

(a)

WRF-CHEM v.4.0 Forecast of dust (ug/kg dryair) 4 April 2000 12:00 UTC

"dust size bin 5: 8.0um effective radius"

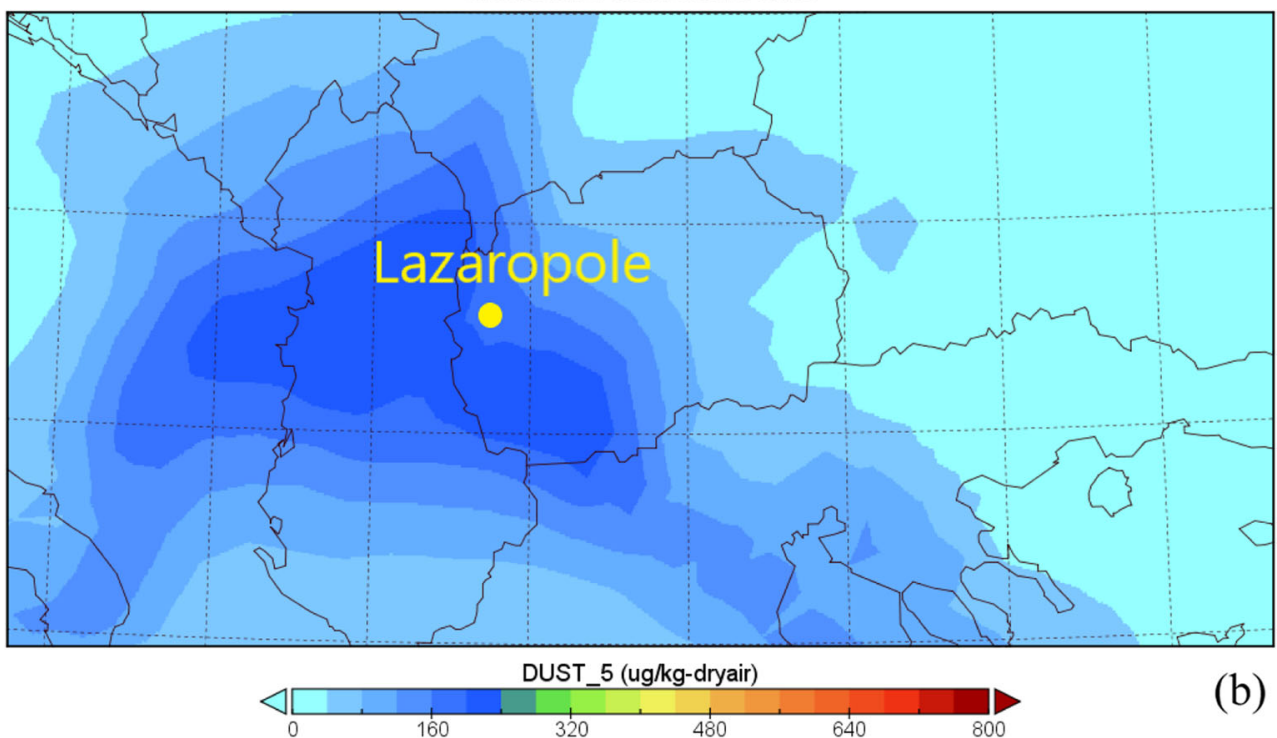

\section{Observational analysis and model setup}

\section{In situ measurements}

The study region of interest is a smaller sub-domain over western part of Macedonia, which is the location of the ground-based sampling meteorological station, "Lazaropole," located in a remote rural representative area with geographical coordinates $\left(\phi=41.5^{\circ}, \lambda=20.7^{\circ}\right.$ and altitude of $1333 \mathrm{~m}$ a.s.l.). The chemical analysis with qualitativequantitative characteristics of precipitation samples collected at the Lazaropole are continuously performed within
European Monitoring Program (EMEP). The considered period covered by this study is April 2000, with special attention on 3 and 4 April, 2000 when considerable dust transport is evidenced, which has impact on the local environmental and chemical composition. Under favorable atmospheric conditions, at such local-scale air pollution episodes, some chemical species (for example $\mathrm{SO}_{2}$ ) indicated that an increase in concentration exceeded international standards of $125 \mu \mathrm{g} / \mathrm{m}^{3}$ as a daily averaged threshold value, for human health protection. The selected case is verified by a chemical analysis of the precipitation measured at the ground-based station Lazaropole area. The precipitation samples are collected every 
24 h with a Wet Only Sampler ARS 1510. Environmental observations and the ambient air quality measurements were carried out within the framework of the European Environmental Program-EMEP. Chemical analysis of anions were carried out using standard UV-VIS method which is based on anion separation, their measurement by conductivity and identification on the basis of retention time as compared to standards, and finally quantification by measurement of peak area. Heavy metal analyses of the collected precipitation in Lazaropole were performed using an atomic absorption spectrometer VARIAN SpectrAA 220. The considered period covered by this study was April 2000, with special attention on 3 and 4 April, when highest concentrations are measured.

\section{WRF-Chem model configuration}

The last released WRF-Chem v. 4.0 model Grell et al. (2005) was configured to simulate the sulfate transport and wet deposition during on 3 and 4 April, when the chemical analysis performed at the environmental station Lazaropole indicated maximum sulfate volume concentration and wet deposition. This coincides well with the date when considerable dust is transported over central Mediterranean, through southern Italy over, SE Europe and western, mainly the mountain part of Macedonia and well captured by the WRF-Chem model forecast with a coarse grid resolution shown on Fig. 1. The GOCART aerosol module has been also incorporated in the model and implemented over a Mediterranean domain without aqueous-phase sulfate chemistry to simulate this specific case study. Three nested runs have been performed with 9-km, 3-km, and 1-km horizontal grid resolution, respectively. The initial fields and boundary conditions were taken from NCEP FNL (Final) Operational Global Analysis data on 1-degree resolution.

\section{Cloud-chemistry model initialization using WRF model}

The local environmental profiles from The Weather Research and Forecasting (WRF) model based on Skamarock et al. (2008) are used to initialize a separate cloud-chemistry model over much smaller sub-domain over Lazaropole. The model has been configured at a significantly refined horizontal and vertical resolution capable of realistically simulating cloudchemistry processes. The physical parameterization package of the model includes planetary boundary layer (PBL), microphysics (MPS), the surface processes, turbulent mixing, convection, radiation, and diffusion. The Noah land-surface scheme is based on Chen and Dudhia (2001). The model microphysics is based on WRF Single-Moment 6-Class (WSM6) microphysics (Hong and Lim 2006). WRF forecasts for each selected day have been performed using NCEP FNL operational global analysis and forecast data on 0.25 by 0.25 degree grids, at each $6 \mathrm{~h}$, interpolated to a WRF single model domain. As this particular event is strongly sensitive to the detailed mesoscale initialization, our basic approach is to employ four different initialization approaches for this experimental setup. The model configurations adopted over three model domains are displayed on Fig. 2. The entire grid system has 38 vertical layers with a terrain following hybrid sigma coordinate, and the model top is located at $50 \mathrm{hPa}$. WRF runs
Fig. 2 The WRF model selected domains. The outer box is domain $1(10 \mathrm{~km})$. The inner boxes denote the domain $2(5 \mathrm{~km})$ and domain $3(2.5 \mathrm{~km})$, respectively, with the location of Lazaropole inserted in the smaller nested domain

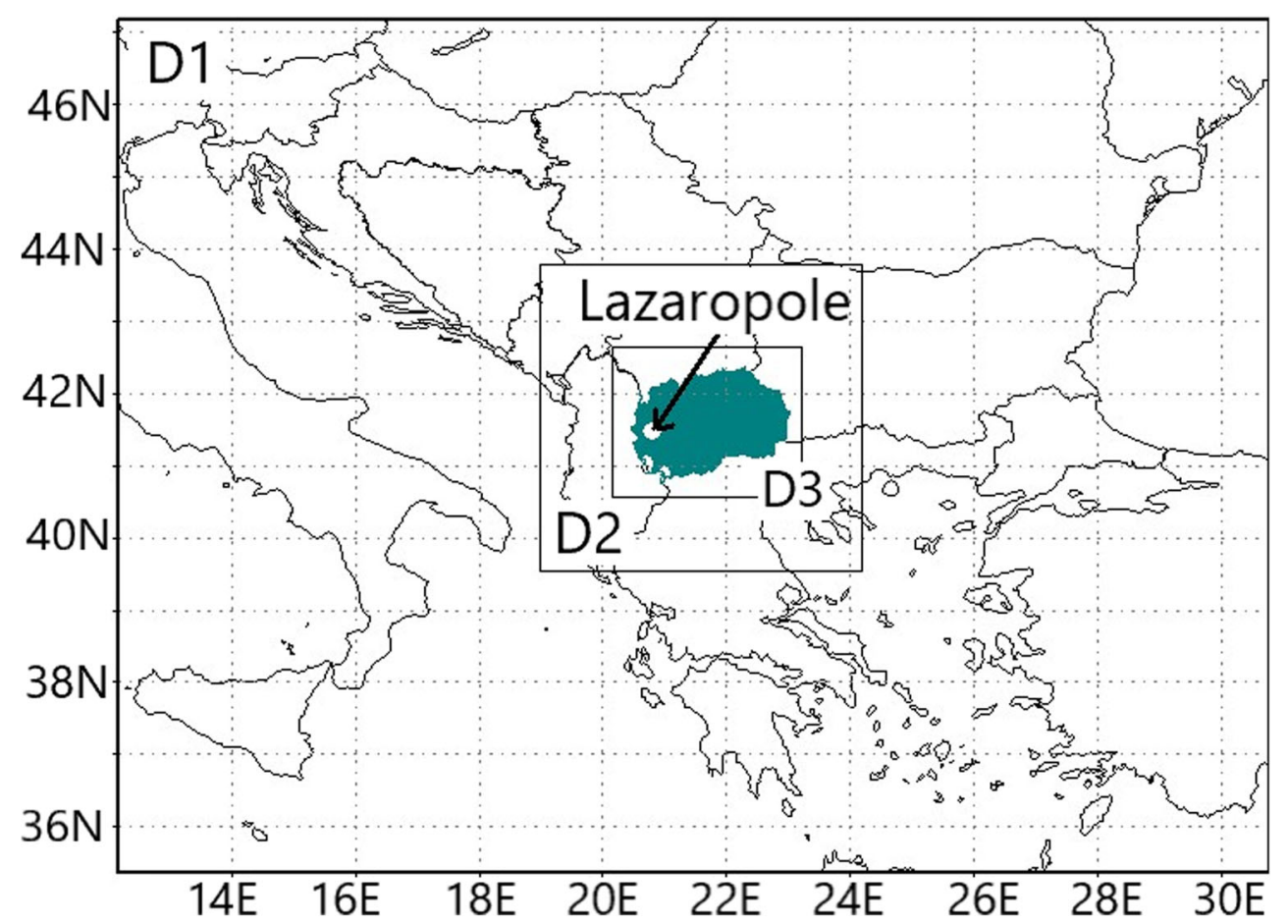


with a 10-, 5-, and 2.5-km grid lengths are initialized on 2 April 2000 at 1200 UTC, with forecast duration of $24 \mathrm{~h}$. The first $12 \mathrm{~h}$ of the simulation represent a spin-up period. The vertical stratification of the atmosphere (potential temperature, specific moisture, and the horizontal velocity components) creates the initial meteorological input for running the model shown in Supplemental Material Fig. S2. An atmospheric profile identifies several important instability features that might be responsible for the initiation and evolution of this convective event. The WRF profiles indicate decrease in potential temperature profile at $3 \mathrm{~km}$ height, moisture deficit at the near surface layer $(2.5 \mathrm{~km})$, and wind veering and enhanced wind shear in PBL layer. Initial meteorological parameters provided from the upper air sounding show relatively lower moisture content, continuous increase of the potential temperature with height, low wind shear in the PBL and enhanced upper level zonal wind compared to WRF profiles. The chemical input data are separately taken and vertically interpolated in the central point of the model domain. The chemical field background used to simulate this case is taken from the measurement dataset for Lazaropole for 3 April 2000 provided by the Ministry of Environment and Physical Planning, Skopje, Macedonia. The initial concentration of $\mathrm{SO}_{2}, \mathrm{H}_{2} \mathrm{O}_{2}, \mathrm{O}_{3}$ and aerosol $\mathrm{SO}_{4}{ }^{2-}$ as pollutant distributions expressed through the mixing ratios are assumed to fall off exponentially, e.g.,

$q_{\mathrm{SO}_{2}}(z)=q_{\mathrm{SO}_{2}}(0) e^{-z / H}$

where $H$ is the scale height. The vertical profiles of sulfate aerosol, sulfur dioxide, ammonia in air $\mu \mathrm{g} \cdot \mathrm{kg}^{-1}$ (air), hydrogen peroxide, and ozone (ppbv) are displayed in Supplemental Material Fig. S3. The initiation of convection is performed using thermal bubble with a minimal temperature perturbation in its centre. This model setup with fine horizontal grid resolution of 0.5 and $0.250 \mathrm{~km}$ vertically gives some advantages in better representation and treatment of the convective scale and chemistry processes which are on a subscale model domain in respect to the numerical scheme. The sensitivity runs have been performed using a three-dimensional version of the model with very fine spatial resolution of $0.5 \mathrm{~km} \times 0.5 \mathrm{~km} \times$ $0.25 \mathrm{~km}$. Since the model equations are compressible, a time-splitting procedure is applied to achieve numerical efficiency and stability. Thus, sound-wave terms are solved separately using a smaller time step $\Delta \mathrm{t}=1 \mathrm{~s}$, while all other equations are treated with a larger time step $\Delta \mathrm{t}=5 \mathrm{~s}$ which is appropriate for the time scales of physical interest. The cloud model domain covers atmospheric volume with dimensions $81 \times$ $81 \times 16 \mathrm{~km}^{3}$ or $161 \times 161 \times 60$ grid points. The initial impulse for convection is the ellipsoidal thermal bubble positioned $15 \mathrm{~km}$ to the left in the central portion of the cloud model domain, at height of $2.0 \mathrm{~km}$. The radial dimensions of the bubble are $x^{*}=15 \mathrm{~km}, y^{*}=15 \mathrm{~km}$, and $z^{*}=3.5 \mathrm{~km}$, respectively. The temperature and velocity perturbations respectively have maximum values in the bubble's center and exponentially decrease toward zero at the bubble's boundaries. The cloud-chemistry sensitivity tests have been performed for a period of $2 \mathrm{~h}$ when atmosphere was convectively unstable. Traditionally, for cloud model initiation and running, we require initial meteorological parameters from upper air sounding measurements and initialization using thermal bubble with maximum temperature perturbation in its center. The present approach proposes cloud model initialization using initial environmental profiles derived from a WRF model. It produces a more detailed information about the local meteorological environment. The initial state setup using the profiles extracted from WRF requires a smaller temperature perturbation of amplitude $1.0 \mathrm{~K}$ added in the center of the domain to initiate convection, relative to cloud model initialization based on the upper air sounding data. Crucially, this cloud-chemistry model has open lateral boundary conditions, so it can freely evolve and produce net ascent/convergence/divergence across its domain without being constrained by the lateral boundary conditions (LBCs) from WRF model. Therefore, the present approach gives some potential advantage in cloud model initialization and initiation of shallow or a deep convection, better treatment of the cloud-chemistry processes and their interaction, which are on subscale in respect to the model and lower central processing unit (CPU) time needed for integration under fine-resolution computing model.

\section{Model results}

Rainfall samples of 3 and 4 April 2000, rich with visible yellowish particles, were analyzed. Aerosol particles partially dissolved in precipitation changed their qualitative and quantitative features, acidity at first, and increased the content of all chemical components. Apparently, the existence of peak values can be noticed on 3 April for all considered parameters. The maximum sulfate volume concentration of $6.69(\mathrm{mg} / \mathrm{l})$ and wet deposition of $42.04 \mathrm{mg} / \mathrm{m}^{2}$ is evidenced on 3 April 2000. The increase of content of all chemical species (e.g., anions, cations, and heavy metals) significantly changed the qualitative-quantitative features and acidity. Figure 3 displays the results from the forecast of the particulate sulfate on 3 April 2000 12:00 UTC and compared with ground-based observation. It is obvious that WRF-Chem model simulations with 9,3, and $1 \mathrm{~km}$ grid-length tend to underpredict the sulfate aerosol concentration. The maximum calculated concentration seen in a finer resolution run is associated with higher emission rate of sulfur dioxide from a lignite mine located in this southwestern portion of the model integration domain. In general, all the sensitivity tests revealed that aqueous-phase oxidation of sulfur dioxide by hydrogen peroxide and ozone, missing in this configuration, leads to this discrepancy. In 
WRF-Chem $9.0 \mathrm{~km}$ forecast of sulfate aerosols (ug $\mathrm{m}^{\wedge}$-3). Valid: 4 Apr 20001200 UTC

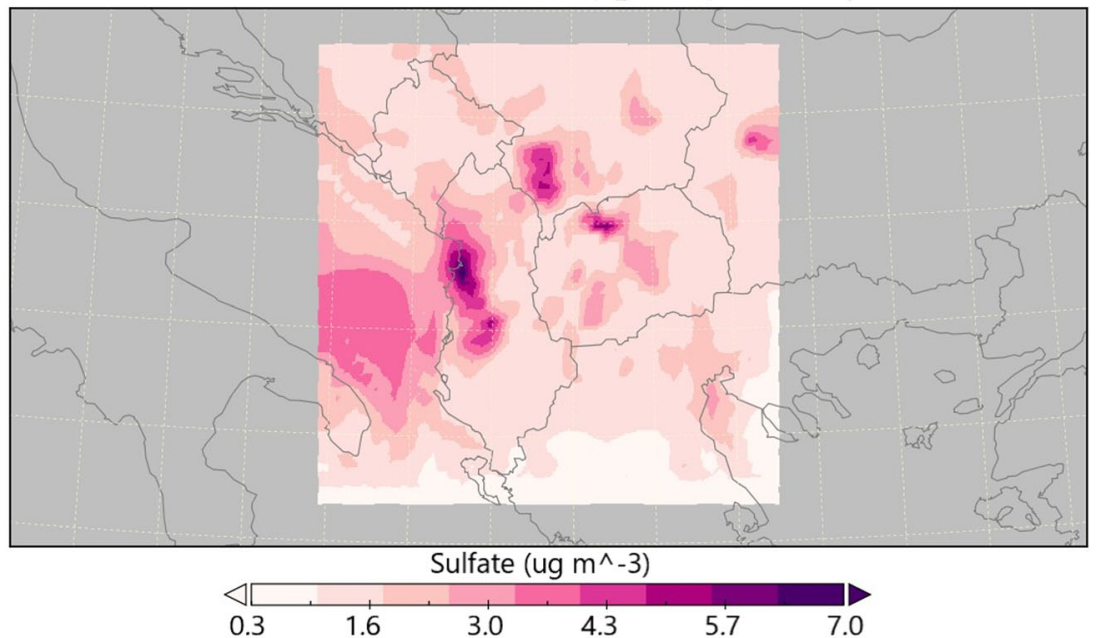

(a)

WRF-Chem $3.0 \mathrm{~km}$ forecast of sulfate aerosols (ug m^-3). Valid: 4 Apr 20001200 UTC

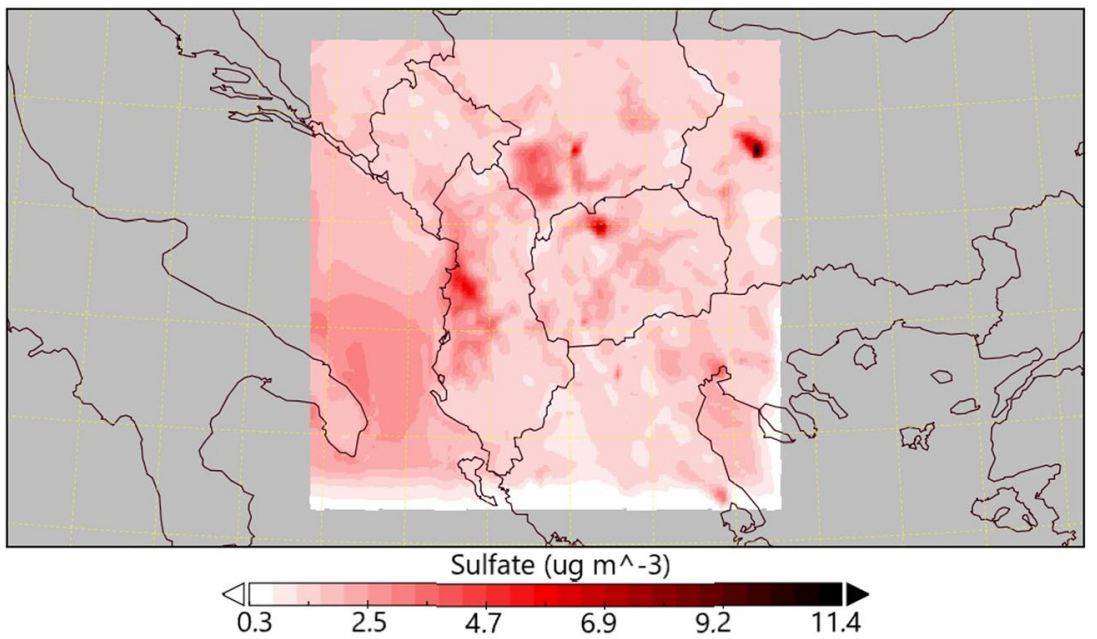

(b)

WRF-Chem $1.0 \mathrm{~km}$ forecast of sulfate aerosols (ug m^^-3). Valid: 4 Apr 20001200 UTC

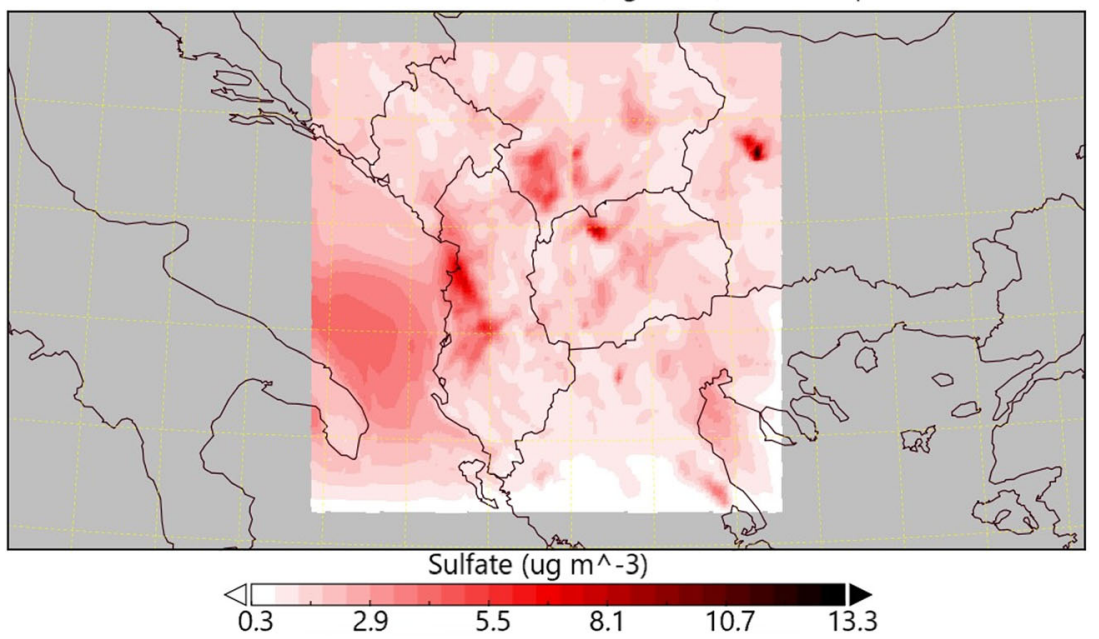

(c)

Fig. 3 a WRF-Chem forecast of particulate sulfate in $\left(\mu \mathrm{g} / \mathrm{m}^{3}\right)$ using 9-km grid resolution, b $3 \mathrm{~km}, \mathbf{c} 1 \mathrm{~km}$ grid resolution, respectively. Model starts 2 April 2000 at 12:00 UTC. Forecast valid: 3 April 2000 12:00 UTC 
order to overcome this problem in our further analysis, we have employed a cloud-resolving model with aqueous-phase sulfate chemistry module. The cloud model is initialized using the local environmental profiles from the WRF model and running in a smaller sub-domain over the location of interest. Two types of sensitivity simulations are conducted: varying the meteorological initialization, and alternately turning off certain chemical processes.

\section{Sulfate chemistry simulations under different initialization}

Cloud-chemistry model running with WRF-derived input is a good choice in case when upper air sounding is missing or its location is on a certain distance from the area of interest (as our case). Thus, the available measurements of vertical stratification of the atmosphere are not really representative and therefore interpolation procedure using a neighborhood method of four adjacent upper air sounding profiles should be applied in order to provide reliable meteorological information. Except the local environment profiles from a location, the topography of the terrain has significant role in the air flow and generation of mesoscale convective instability. The western part of Macedonia is surrounded with mountains, where updraft motion is forced when a moving air mass encounters the rising slope of a mountain ridge. The atmospheric conditions on 3 April 2000 were favorable for initiation of enhanced convection which tends to develop when moist instability coincides with sufficient terrain-induced ascent to locally overcome convective inhibition. At such unstable atmospheric conditions, the upper meteorological station evidenced increased concentrations of all chemical elements. The primary reason for that is enhanced convection forcing by the topography, having impact on the horizontal vertical transport of pollutants as it is found by Vujović et al. (2014), processing of aerosols in a mixed-phase convective cloud and significant influence on the gas redistribution, sulfate production, and wet deposition.

The first model run is specified by meteorological parameters obtained from an observed upper air sounding. Other numerical simulations have been initialized from WRF model forecasts with $10 \mathrm{~km}, 5 \mathrm{~km}$, and $2.5 \mathrm{~km}$ grid resolution. Figure 4 depicts the vertical cross-sections of sulfate volume concentration in $25 \mathrm{~min}$, at the most intense phase of cloud evolution, using a different model initialization. It is apparent that simulation with the upper air sounding initialization shows a more uniform distribution of sulfate aerosol mass. The sulfate concentration averaged over the simulation time indicates much lower value relative to measured volume concentration at the meteorological station Lazaropole. The similar result with slightly higher sulfate concentration of $4.2 \mathrm{mg} / 1$ is obtained using initialization with $10 \mathrm{~km}$-scale WRF model and applying cumulus parameterization. The cloud model simulation with initial meteorological parameters derived from 5.0- and $2.5 \mathrm{~km}$-scale WRF model forecasts and explicit treatment of convection shows a more detailed representation of the sulfate aerosol transport and redistribution and thus a better quantitative estimation of the sulfate volume concentration of $7.0 \mathrm{mg} / 1$ which is similar to that obtained from laboratory measurement. That is mainly due to better initial meteorological input and finer spatial and temporal resolution of cloud model that is capable to resolve the convective scale processes in more detail. These factors are dominant for cloud-chemical processes interaction and the modification of sulfate concentration which influences on sulfate budget and acidity of precipitation.

\section{Spatial distributions of sulfate aerosols}

We continue with the examination of the spatial distributions of sulfate aerosol in condensate phase from 5 to $60 \mathrm{~min}$ of the simulation time as depicted in Supplemental Material Fig. S4. The dashed curve delineates the cloud boundary, while the solid curves represent isopleths of sulfate expressed as volume concentration. The numerical simulation has shown initial convection evolved from a stratified cloud environment. We note a near cloud base convergence detected in the vortex area embedded between forward flank updraft and rear flank downdraft region. The rapid vertical transport of sulfate in the cloud developing stage is due to updraft and the mass transfer by nucleation scavenging of the sulfate particulate matter. The nucleation process of sulfate aerosol is important as it represents the primary activation of cloud condensation nuclei $(\mathrm{CCN})$. The nucleation efficiency indicates that 80 $100 \%$ of the total aerosol mass is activated and incorporated into cloud drops when there is condensation. This process occurs at a cloud base, and the numerical simulation indicates an increased concentration at the initial stage of cloud evolution at the cloud base. Subsequently, sulfate parcel with relatively lower concentration is advected and diffused by the turbulent flow toward the upper portion of the cloud. Early formation of rainfall contributed in acceleration of the microphysical transfer process among water categories and sulfate mass conversions between other chemical species participating in sulfate production and wet deposition. After this, the updrafts are not sufficient to maintain sulfate mass at the cloud base, and washout by rain gradually reduced cloud dissolved sulfate. From $40 \mathrm{~min}$ of the simulation time, enhanced zonal circulation at the upper levels move the sulfate mass in the central part of the model domain, contributing to more uniform distribution of sulfate. It is seen that the rain-loaded sulfate in small fractions reaches the ground leading to wet deposition. Soon after that, when the cloud enters dissipation stage, a new cloud movement and activity is detected at the inner portion of the cloud model domain.

The spatial distribution of $\mathrm{H}_{2} \mathrm{O}_{2}, \mathrm{O}_{3}, \mathrm{NH}_{4}{ }^{+}, \mathrm{SO}_{2}$ and $\mathrm{SO}_{4}{ }^{2-}$ of chemical species participating in sulfate production and wet 
Fig. 4 Spatial distributions of sulfate volume concentration $(\mathrm{mg} / \mathrm{l})$ in $25 \mathrm{~min}$ of the simulation time on 3 April 2000 12:00 UTC, using a different model initialization
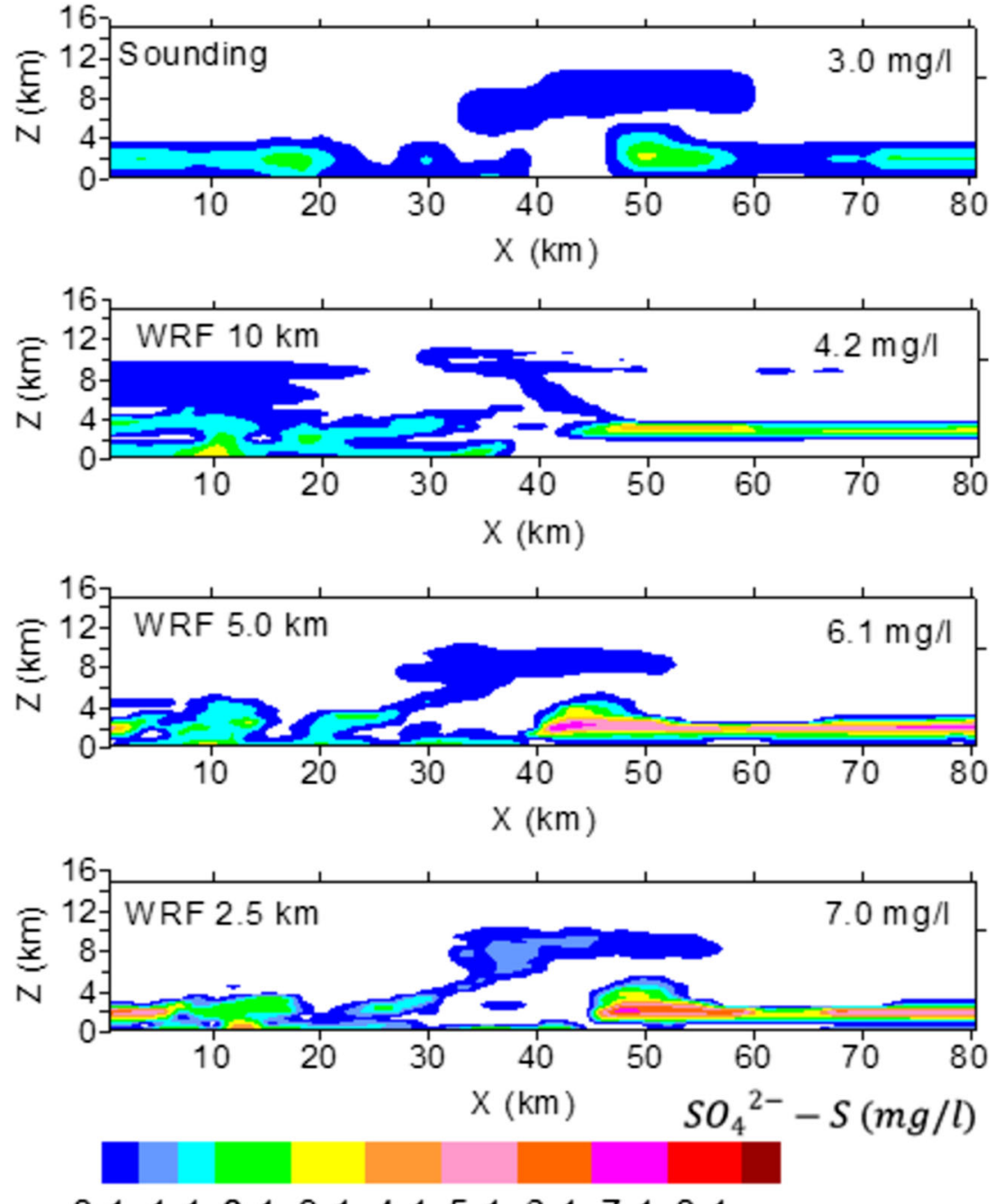

$\begin{array}{llllllllll}0.1 & 1.1 & 2.1 & 3.1 & 4.1 & 5.1 & 6.1 & 7.1 & 8.1\end{array}$ deposition during most intense stage of cloud evolution is shown in Supplemental Material Fig. S5. We note a more rapid vertical transport of ozone, hydrogen peroxide, and sulfate maximum concentration and a maximum mixing ratio located near the central part of the simulated cloud.

The vertical profiles of microphysical fields, wind structure, updrafts, and downdrafts displayed on Fig. 5 indicate the importance of physical processes upon sulfate chemistry. The formation of rain gradually reduces the mass of dissolved sulfate. After that, formation of anvil becomes apparent. A new cell is initiated at the outflow boundary on the downshear side of the convective cloud between updraft and downdraft regions in the lower part of the atmosphere. It is accompanied by a strong vertical gradient of sulfate aerosols at cloud base as the result of sulfate mass transfer by nucleation scavenging. Here, the maximum concentration of sulfate aerosol mass is apparent.

We have also examined the relative importance of scavenging, oxidation, and ice-phase processes in the model (see Supplement Material), which influences the sulfate budget and acidity. In addition to aforementioned processes, we have also applied a fully explicit calculation of gas dissolution in cloud water. The results from this numerical simulation are compared with the base run. The vertical profiles of sulfate aerosol, alternately turning off certain chemical processes which influence on sulfate production and wet removal, are exhibited in Supplement Material Fig. S6.

The sulfate wet deposition and the acidity of precipitation can be estimated using the simulated $\mathrm{pH}$ factor. Vertical distribution of cloud water $\mathrm{pH}$ at the most intense phase of evolution, using a different model initialization, is displayed in Fig. 6a. The main characteristics of the diagram are the strong vertical gradient and similar pattern distributions of cloud water $\mathrm{pH}$ during development phase of cloud evolution. The difference between the vertical distributions of $\mathrm{pH}$ inside the cloud is more evident in run with $2.5 \mathrm{~km}$ initialization as the result of early dissolution of pollutant near the cloud base relative to other runs. The rainwater $\mathrm{pH}$ (see Fig. 6b) shows a strong gradient at the near surface layer with spatial displacement of the shapes in all runs derived from WRF forecasts with an averaged $\mathrm{pH}$ value decreased to 4.5 in $2.5 \mathrm{~km}$ run. On the other hand, the simulation using upper air 
Fig. 5 a Spatial distribution of microphysical fields and sulfate aerosol expressed through the mixing ratios in $25 \mathrm{~min}$ of the simulation time on 3 April 2000 12:00 UTC, using a 2.5-km NWP model initialization. b Cloud sequence together vertical profile of wind field within the cloud model integration domain. $\mathbf{c}$ Updrafts and downdrafts $(\mathrm{m} / \mathrm{s})$. Black curve delineates the cloud outline with mixing ratio greater than $0.1 \mathrm{~g} / \mathrm{kg}$

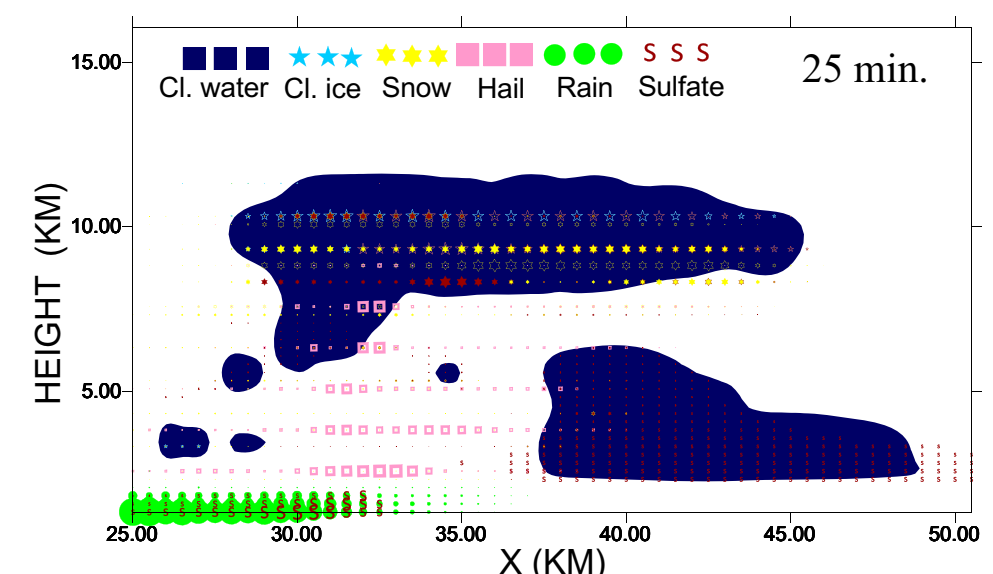

(a)
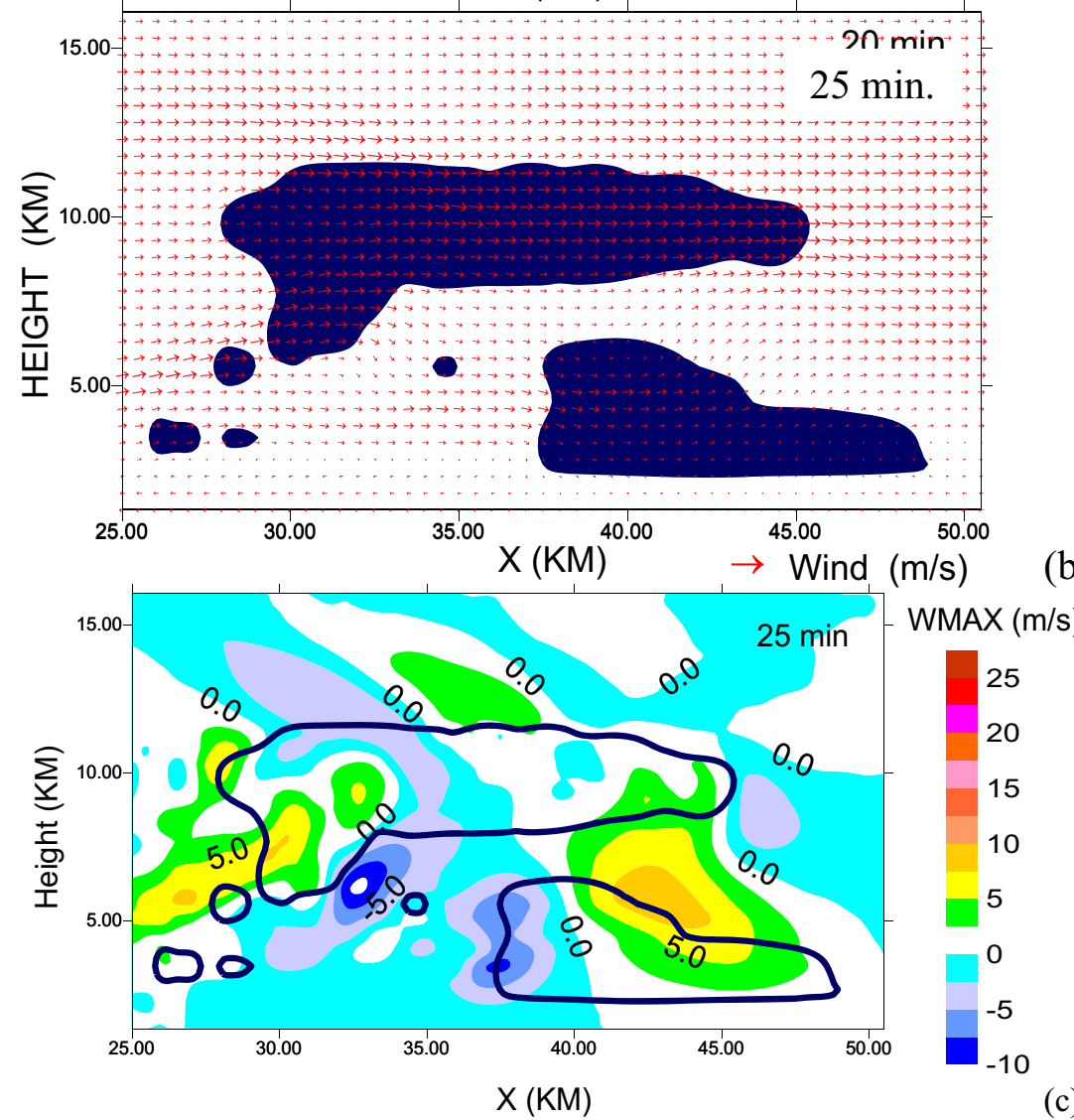

sounding as model initialization and initial data input, the rainwater $\mathrm{pH}$ develops into an irregular shape (not shown) followed by a weakening as the results of early washout and partial evaporation.

\section{Comparative analysis and verification of the results}

Results obtained using this coupled cloud-chemistry model have also been compared with available in situ physical and chemical measurements at the meteorological station Lazaropole. The comparison between the simulated parameters (precipitation, sulfate volume concentration, wet deposition, and rainwater $\mathrm{pH}$ ), with observations during March-April 2000, is depicted in Supplemental Material Fig. S7. In general, there is a relatively good agreement between the measured and simulated results during the entire analyzed period. The difference between the results becomes more evident when cloud-chemistry model is initialized with upper air sounding data and 10-km-scale WRF model. It is apparent that the maximum amount of rainfall, $\mathrm{pH}$, sulfate volume concentration $(\mathrm{mg} / \mathrm{l})$, and sulfate wet deposition $\left(\mathrm{mg} / \mathrm{m}^{2}\right)$ is measured on 4 April 2000 . Here, $2.5 \mathrm{~km}$ run shows quite reasonable values of sulfate aerosol concentration and $\mathrm{pH}$. 

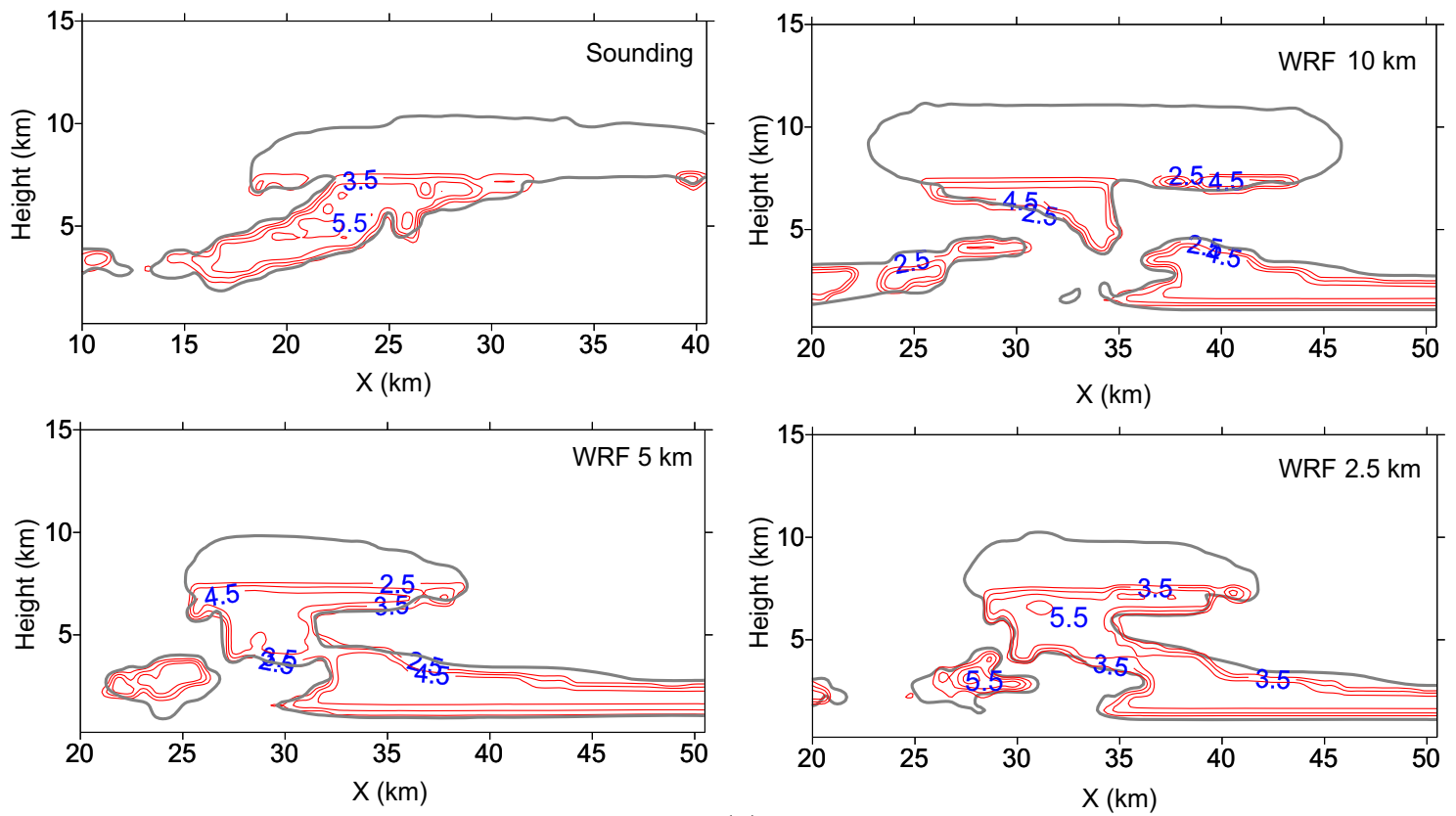

(a)
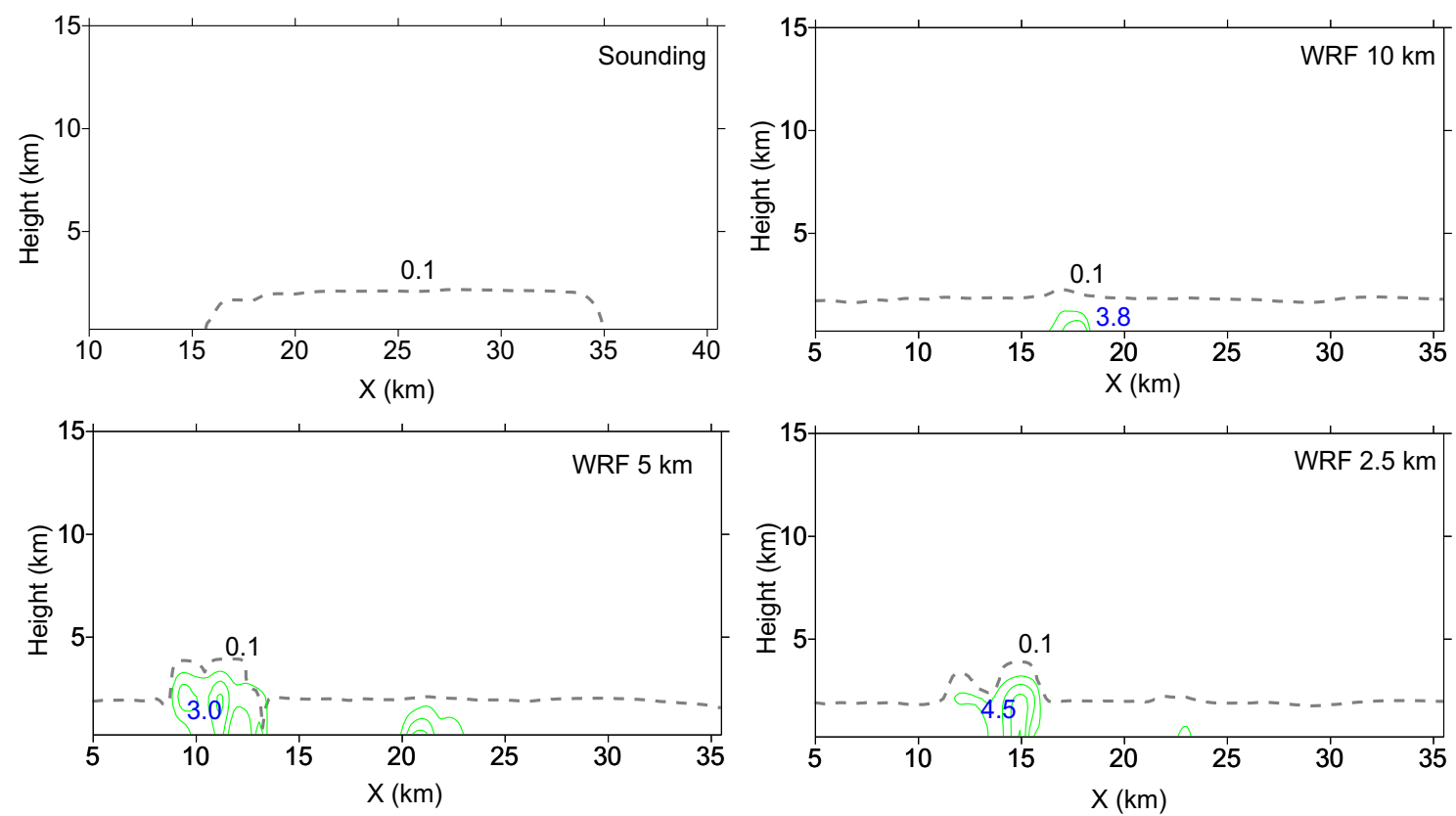

(b)

Fig. 6 a Vertical profile of cloud water $\mathrm{pH}$ during developing phase of cloud using a different model initialization. b Same as Fig. 12a but for rainwater pH

The quantitative verification of the simulation results using different initializations has been also applied using standard statistical methods. Table 1 lists the linear bias or mean error (BIAS), mean absolute error (MAE), root mean square error (RMSE), and the correlation coefficient (CC). The verification has been provided for meteorological and chemical model outputs for the whole examined period. The mean error (ME) as measure of overall reliability indicates the averaged direction of error. The negative mean algebraic errors indicate under-forecast of precipitation. A 2.5 run shows a slightly positive mean error which means more accurate simulation and thus better agreement with the observations. The difference between cloud-chemistry simulations is more evident considering the average magnitude of the errors (MAE and RMSE). The evaluated results implied that a greater magnitude of errors are determined for precipitation and wet deposition, for cloud model run initialized with upper air sounding data and those based on WRF model with coarser grid resolution. A cloud-chemistry model initialized with the local environmental profiles from a $2.5-\mathrm{km}$-scale WRF shows a better 
Table 1 Quantitative verification of forecast results using a different model initialization

\begin{tabular}{|c|c|c|c|c|}
\hline $\begin{array}{l}\text { Verification } \\
\text { method/parameter- } \\
\text { initialization }\end{array}$ & $\begin{array}{l}\text { Linear bias }=\text { mean } \\
\text { error-BIAS ME }= \\
\left(\sum w_{i}\left(f_{i}-a_{i}\right)\right) / \sum_{i=1}^{n} w_{i}\end{array}$ & $\begin{array}{l}\text { Mean absolute error-MAE } \\
\text { MAE }=\left(\sum w_{i}\left|\left(f_{i}-a_{i}\right)\right|\right) / \sum_{i=1}^{n} w_{i}\end{array}$ & $\begin{array}{l}\text { Root mean square } \\
\text { error-RMSE RMSE }= \\
\sqrt{\sum_{i=1}^{n} w_{i}\left(f_{i}-a_{i}\right)^{2}} / \sqrt{\sum_{i=1}^{n} w_{i}}\end{array}$ & $\begin{array}{l}\text { Correlation coefficient-CC } \\
\mathrm{CC}=\frac{\sum_{i=1}^{n} w_{i}\left(f_{i}-\bar{f}\right)\left(a_{i}-\bar{a}\right)}{\sqrt{\sum_{i=1}^{n} w_{i}\left(f_{i}-\bar{f}\right)^{2} \sum_{i=1}^{n} w_{i}\left(a_{i}-\bar{a}\right)^{2}}}\end{array}$ \\
\hline \multicolumn{5}{|l|}{ Rainfall (mm) } \\
\hline $2.5 \mathrm{~km}$ & -0.164 & 0.773 & 1.121 & 0.731 \\
\hline $5.0 \mathrm{~km}$ & -0.023 & 1.248 & 1.704 & 0.520 \\
\hline $10.0 \mathrm{~km}$ & -1.872 & 1.881 & 2.804 & 0.315 \\
\hline Sounding & -1.860 & 2.240 & 3.204 & 0.343 \\
\hline \multicolumn{5}{|c|}{ Vol. conc. $\mathrm{SO}_{4}^{-2}-\mathrm{S}(\mathrm{mg} / \mathrm{l})$} \\
\hline $2.5 \mathrm{~km}$ & 0.150 & 0.191 & 0.371 & 0.6120 \\
\hline $5.0 \mathrm{~km}$ & -0.043 & 0.209 & 0.030 & 0.3270 \\
\hline $10.0 \mathrm{~km}$ & -0.086 & 0.446 & 0.752 & 0.2512 \\
\hline Sounding & -1.860 & 2.240 & 3.204 & 0.2138 \\
\hline \multicolumn{5}{|c|}{ Wet dep. $\mathrm{SO}_{4}^{-2}-\mathrm{S}\left(\mathrm{mg} / \mathrm{m}^{2}\right)$} \\
\hline $2.5 \mathrm{~km}$ & 0.105 & 0.847 & 1.744 & 0.438 \\
\hline $5.0 \mathrm{~km}$ & -3.455 & 3.590 & 10.89 & 0.2452 \\
\hline $10.0 \mathrm{~km}$ & -1.530 & 2.210 & 5.170 & 0.1347 \\
\hline Sounding & -1.800 & 2.600 & 5.070 & 0.0952 \\
\hline \multicolumn{5}{|l|}{$\mathrm{pH}$ (rainwater) } \\
\hline $2.5 \mathrm{~km}$ & -0.076 & 0.258 & 0.406 & 0.6944 \\
\hline $5.0 \mathrm{~km}$ & -0.011 & 0.389 & 0.476 & 0.530 \\
\hline $10.0 \mathrm{~km}$ & 0.014 & 0.456 & 0.579 & 0.4180 \\
\hline Sounding & 0.053 & 0.556 & 0.692 & 0.194 \\
\hline
\end{tabular}

skill in more accurate simulation of all listed parameters and thus a higher averaged correlation coefficient of 0.619 with corresponding measurements, relative to the other runs, respectively.

\section{Concluding remarks}

A cloud model coupled with sulfate chemistry sub-model has been used to examine the sulfate production and wet deposition over a rural location in Macedonia during March-April 2000. More significantly, this model runs with an open lateral boundary conditions. It allows simulation of convection and associate processes across its domain without being constrained by the lateral boundary conditions (LBCs) from WRF model. Therefore, the present method gives some potential advantage in cloud model initialization and initiation of shallow or a deep convection and better simulation of the cloud-chemistry processes. A set of numerical experiments has been performed with WRF model conditions, using different horizontal grid resolution. Our main motivation is to evaluate the model ability and its performance in simulation of aqueous-phase sulfate chemistry in convective cloud. The cloud-chemistry model is initialized with an ellipsoidal thermal bubble with minimal temperature perturbation of $0.2(\mathrm{~K})$ in the bubble center. The chemical field initialization is based on the vertical distribution profile of chemical species participating in sulfate chemistry provided from the laboratory measurements at Lazaropole station using standard chemical analysis of rainfall samples, carried out within the EMEP Programme. The analysis shows that the maximum volume concentration of $\mathrm{SO}_{4}{ }^{2-}$, $\mathrm{pH}$ value, and wet deposition is measured on 3 April 2000 when considerable dust was transported into atmosphere. Numerical simulation with initialization derived from 2.5$\mathrm{km}$-scale WRF model forecast and explicit treatment of convection provides a more realistic simulation of the structural and evolution properties of cloud with chemistry during the whole life cycle of cloud and better represents the cloud-chemistry interactions and the modification of the pollutant concentration. It is evident that simulated sulfate concentration averaged over simulation time is very close to measured volume concentration compared to other runs, which use upper air sounding data as meteorological input and WRF forecast with 10 grid increment 
and cumulus parameterization. The study also includes the examination of the relative importance of scavenging, oxidation, and ice-phase processes to sulfate production and wet deposition. Most of the sulfate aerosol production occurs in cloud developing phase when in-cloud oxidation of $\mathrm{SO}_{2}$ by $\mathrm{H}_{2} \mathrm{O}_{2}$ and $\mathrm{O}_{3}$ takes place. The sensitivity tests revealed that scavenging and oxidation contribute for about 33 and $46 \%$ in sulfur production, while ignoring the ice-phase chemistry leads to overprediction of sulfate for about $8 \%$ relative to the base run using WRF $2.5 \mathrm{~km}$ initialization. The comparative analysis has shown a relatively good agreement between simulated and measured data during the entire analyzed period with exception to total accumulated rainfall and the amount of wet deposition which in our study refers to $120 \mathrm{~min}$ simulation. The results obtained using $2.5 \mathrm{~km}$ WRF model initialization indicate a slightly positively linear bias (BIAS) and consequently smaller root mean square errors (RMSEs), relative to other runs, and thus a better accuracy of all simulated parameters. In addition, a relatively high correlation coefficient found for rainfall (0.731), sulfate volume concentration $(0,612)$, sulfate wet deposition (0.438), and rainwater $\mathrm{pH}(0.694)$, respectively, show the cloud-chemistry model performance in more realistic simulation and better qualitative-quantitative assessment of cloud-aerosol processes and their interactions over a smaller environmental domain. The differences are more apparent when upper air sounding and coarser WRF forecast is used to initialize the cloud-chemistry model runs. As summary, the model sensitivity experiments which utilize this method of initialization derived from WRF model conditions with fine horizontal grid resolution provide better representation of the local meteorological environment as important ingredient for cloud initiation and simulation of the convective-scale processes which are responsible for cloud evolution, cloud-chemistry interactions and transformation, sulfate production, and subsequent deposition. Even though this novel method showed some advances and potential in more realistic simulation of cloud-aerosol processes, our overall conclusion is still limited and restrained due to the fact that only a single case is examined. However, the results from these preliminary tests give some potential added value for further testing and evaluations of other cases. Our work will be further focused on improvement of the method by examination of microphysical and chemical transfer processes in convective clouds, utilizing a different model configuration and initialization applying advanced verification methods which will allow a better evaluation of the results and more reliable qualitative-quantitative air quality assessment.

Acknowledgements Open access funding provided by University of Vienna. The authors wish to express their appreciation to the Hydrometeorological Service of Macedonia for provision of chemical measurements for Lazaropole station during March-April 2000 and also to Ministry of Environmental and Physical Planning for additional air quality data. We kindly acknowledge Prof. Gabriel Pereira from the Department of Geosciences Federal University of São João del Rei
(UFSJ), Brazil, for his assistance in preparation of the chemistry preprocessing and emission data. The useful suggestions given by the editor-in-chief and valuable comments and recommendations from the anonymous reviewers which significantly helped for manuscript improvement are very much appreciated.

Open Access This article is distributed under the terms of the Creative Commons Attribution 4.0 International License (http:// creativecommons.org/licenses/by/4.0/), which permits unrestricted use, distribution, and reproduction in any medium, provided you give appropriate credit to the original author(s) and the source, provide a link to the Creative Commons license, and indicate if changes were made.

Publisher's note Springer Nature remains neutral with regard to jurisdictional claims in published maps and institutional affiliations.

\section{References}

Bae SY, Park RJ, Kim YP, Woo J-H (2012) Effects of below-cloud scavenging on the regional aerosol budget in East Asia. Atmos Environ $58: 14-22$

Barth MC, Stuart AL, Skamarock WC (2001) Numerical simulations of the July 10 STERAO/deep convection storm: redistribution of soluble tracers. J Geophys Res 106(12):381-312 400

Barth MC, Kim S-W, Skamarock WC, Stuart AL, Pickering KE, Ott LE (2007a) Simulations of the redistribution of formaldehyde, formic acid, and peroxides in the 10 July 1996 stratospheric-tropospheric experiment: radiation, aerosols, and ozone deep convection storm. $\mathrm{J}$ Geophys Res 112:D13310. https://doi.org/10.1029/2006JD008046

Barth MC, Kim S-W, Wang C, Pickering KE, Ott LE, Stenchikov G, Leriche M, Cautenet S, Pinty JP, Barthe C, Mari C, Helsdon JH, Farley RD, Fridlind AM, Ackerman AS, Spiridonov V, Telenta B (2007b) Cloud-scale model intercomparison of chemical constituent transport in deep convection. Atmos Chem Phys 7:4709-4731

Barth MC, Bela MM, Fried A, Wennberg PO, Crounse JD, St. Clair JM, Blake NJ, Blake DR, Homeyer CR, Brune WH, Zhang L, Mao J, Ren X, Ryerson TB, Pollack IB, Peischl J, Cohen RC, Nault BA, Huey LG, Liu X, Cantrell CA (2016) Convective transport of peroxides by thunderstorms observed over the central U.S. during DC3. J Geophys Res Atmos. https://doi.org/10.1002/2015JD024570

Bela MM, Barth MC, Toon OB, Fried A, Homeyer CR, Morrison H, Cummings KA, Li Y, Pickering KE, Allen DJ, Yang Q, Wennberg PO, Crounse JD, St. Clair JM, Teng AP, O'Sullivan D, Huey LG, Chen D, Liu X, Blake DR, Blake NJ, Ape EC, Hornbrook RS, Flocke F, Campos T, Diskin D (2016) Wet scavenging of soluble gases in DC3 deep convective storms using WRF-Chem simulations and aircraft observations. J Geophys Res Atmos 121:4233-4257. https://doi.org/10.1002/2015JD024623

Berg L, Shrivastava K, Easter N, Fast RC, Chapman EG, Liu Y, Ferrare RA (2015) A new WRF-Chem treatment for studying regional-scale impacts of cloud processes on aerosol and trace gases in parameterized cumuli. Geosci Model Dev 8:409-429

Chen F, Dudhia J (2001) Coupling an advanced land surface-hydrology model with the Penn State-NCAR MM5 Modelling system. Part I: model implementation and sensitivity. Mon Weather Rev 129:569-585

Cohan DS, Schultz MG, Jacob DJ, Heikes BG, Blake DR (1999) Convective injection and photochemical decay of peroxides in the tropical upper troposphere: methyl iodide as a tracer of marine convection. J Geophys Res 104:5717-5724 
Crutzen PJ, Lawrence MG (2000) The impact of precipitation scavenging on the transport of trace gases: a 3-dimensional model sensitivity study. J Atmos Chem 37:81-112

Easter RC, Hales JM (1983) Interpretation of the OSCAR data for reactive gas scavenging. In: Pruppacher HR, Semonin RG, Slinn WG (eds) Precipitation Scavenging, Dry Deposition, and Resuspension. Elsevier, Amsterdam, pp 649-662

Ekman AM, Wang C, Wilson J, Strom J (2004) Explicit simulation of aerosol physics in a cloud resolving model. Atmos Chem Phys Discuss 4:753-803

Ekman AM, Wang C, Strom J, Krejci R (2006) Explicit simulation of aerosol physics in a cloud-resolving model: aerosol transport and processing in the free troposphere. J Atmos Sci 63:693-696

Giorgi F, Chameides WL (1986) Rainout lifetimes of highly soluble aerosols and gases as inferred from simulations with a general circulation model. J Geophys Res 91(14):367-14 376

Grell GA, Peckham SE, Schmitz R, McKeen SA, Frost G, Skamarock WC, Eder B (2005) Fully coupled 'online' chemistry in the WRF model. Atmos Environ 39:6957-6976

Hales JM (1982) Mechanistic analysis of precipitation scavenging using a one-dimensional time variant model. Atmos Environ 16:177-1783

Hong SY, Lim JJ (2006) The WRF single-moment 6-class microphysics scheme (WSM6). J Korean Meteorol Soc 42(2):129-151

Janjic Z, Black T, Pyle M, Rogers E, Chuang HY, DiMego G (2005) High resolution applications of the WRF-NMM NMM. Preprints, 21st Conference on Weather Analysis and Forecasting/17th Conference on Numerical Weather Prediction, Amer. Meteor. Soc., Washington, DC. CD-ROM 16A.4.

Kallos G, Astitha M, Katsafados P, Spyrou C (2007) Long-range transport of anthropogenically and naturally produced particulate matter in the Mediterranean and North Atlantic: current state of knowledge. J Appl Meteorol Climatol 46:1230-1251

Kallos G, Papadopoulos A, Katsafados P, Nickovic S (2006) TransAtlantic Saharan dust transport: model simulation and results. J Geophys Res 111:D09204. https://doi.org/10.1029/2005JD006207

Klemp JB, Wilhelmson RB (1978) The simulation of three-dimensional convective storm dynamics. J Atmos Sci 35:1070-1096

Kreidenweis SM, Zhang Y, Taylor GR (1997) The effects of clouds on aerosol and chemical species production and distribution, 2. Chemistry model description and sensitivity analysis. J Geophys Res 102:23,867-23,882

Langmann B, Varghese S, Marmer E, Vignati E, Wilson J, Stier P, O’Dowd C (2008) Aerosol distribution over Europe: a model evaluation study with detailed aerosol microphysics. Atmos Chem Phys 8:1591-1607

Lin YL, Farley RD, Orville HD (1983) Bulk water parameterization in a cloud model. J Clim Appl Meteorol 22:1065-1092

Niewiadomski M (1989) Sulfur dioxide and sulfate in a threedimensional field of convective clouds: numerical simulations. Atmos Environ 23(2):477-487

Orville HD, Kopp FJ (1977) Numerical simulation of the history of a hailstorm. J Atmos Sci 34:1596-1618

Pérez C, Haustein K, Janjic Z, Jorba O, Huneeus N, Baldasano JM, Black T, Basart S, Nickovic S, Miller RL, Perlwitz J, Schulz M, Thomson M (2011) An online mineral dust aerosol model for meso to global scales: model description, annual simulations and evaluation. Atmos Chem Phys 11:13001-13027

Skamarock WC, Klemp JB, Dudhia J, Gill DO, Barker DM, Duda M, Huang X-Y, Wang W, Powers JG (2008) A description of the advanced research WRF, version 3 (NCAR Technical Note No. NCAR/T475 + STR). National Center for Atmospheric Research, Boulder

Spyrou C, Mitsakou C, Kallos G, Louka P, Vlastou G (2010) An improved limited area model for describing the dust cycle in the atmosphere. J Geophys Res 115:D17211. https://doi.org/10.1029/ 2009JD013682
Spiridonov V, Ćurić M (2003) A three-dimensional numerical simulation of sulfate transport and redistribution. Can J Phys 81: 1067-1094

Spiridonov V, Ćurić M (2005) The relative importance of scavenging, oxidation and ice-phase processes in production and wet deposition of sulfate. J Atmos Sci 62:2118-2135

Spiridonov V, Curić M (2009) Numerical simulation of physical and chemical processes in convective clouds. Asia-Pac J Atmos Sci 45:1

Stuart AL, Jacobson MZ (2003) A timescale investigation of volatile chemical retention during hydrometeor freezing: nonrime freezing and dry growth riming without spreading. J Geophys Res 108(D6): 4178

Tao W-K, Chen J-P, Li Z, Wang C, Zhang C (2012) Impact of aerosols on convective clouds and precipitation. Rev Geophys 50:RG2001. https://doi.org/10.1029/2011RG000369

Taylor GR (1989) Sulfate production and deposition in mid-latitude continental cumulus clouds II, Chemistry model formulation and sensitivity analysis. J Atmos Sci 46(13):1991-2007

Telenta B, Aleksic N (1988) A three-dimensional simulation of the 17 June 1978 HIPLEX case with observed ice multiplication. 2nd International Cloud Modeling Workshop, Toulouse, 8-12 August 1988. WMO/TD No. 268, pp 277-285

Tremblay A, Leighton H (1986) A three-dimensional cloud chemistry model. J Clim Appl Meteorol 25:652-671

Tuccella P, Curci G, Visconti G, Bessagnet B, Menut L, Park RJ (2012) Modeling of gas and aerosol with WRF/Chem over Europe: evaluation and sensitivity study. J Geophys Res 117:D03303. https://doi. org/10.1029/2011JD016302

Vujović D, Vučković V, Curić M (2014) Effect of topography on sulfate redistribution in cumulonimbus cloud development. Environ Sci Pollut Res 21:3415-3426

Walcek CJ, Taylor GR (1986) A theoretical method for computing vertical distributions of acidity and sulfate production within cumulus clouds. J Atmos Sci 43(4):339-355

Wang C, Chang JS (1993a) A three-dimensional numerical model of cloud dynamics, microphysics and chemistry, 4. Cloud chemistry and precipitation chemistry. J Geophys Res 98: 116,799-116,808

Wang C, Chang JS (1993b) A three-dimensional numerical model of cloud dynamics, microphysics, and chemistry, 1.Concepts and formulation. J Geophys Res 98:14,827-17,844

Wang C, Crutzen PJ (1995) Impact of a simulated severe local storm on the redistribution of sulfur dioxide. J Geophys Res 100(D6):11,35711,367

Wang C, Prinn RG (1998) Impact of the horizontal wind profile on the convective transport of chemical species. J Geophys Res 103(D17): 22,063-22,071

Wang C, Prinn RG (2000) On the roles of deep convective clouds in tropospheric chemistry. J Geophys Res 105:22,269-22,297

Wonaschuetz A, Sorooshian A, Ervens B, Chuang PY, Feingold G, Murphy S, Gouw J, de Warneke C, Jonsson HH (2012) Aerosol and gas re-distribution by shallow cumulus clouds: an investigation using airborne measurements. J Geoophys Res-Atmos 117(D17202):1-18

Yerramilli A, Rao Dodla VB, Challa VS, Myles LT, Pendergrass WR, Vogel CA, Dasari HP, Tuluri F, Baham JM, Hughes RL, Patrick C, Young JH, Swanier SJ, Hardy MG (2012) An integrated WRF/ HYSPLIT modeling approach for the assessment of PM2.5 source regions over the Mississippi Gulf Coast region. Air Qual Atmos Health 5:401-412

Yin Y, Parker DJ, Carslaw KS (2001) Simulation of trace gas redistribution by convective clouds-Liquid phase processes. Atmos Chem Phys 1:19-36 